\title{
Fenofibrate treatment of rats with experimental autoimmune myocarditis by alleviating Treg/Th17 disorder
}

\author{
HUILEI CHENG ${ }^{1}$, YANQIN XI ${ }^{1}$ XIANNA CHI ${ }^{1}$ YANXIA WU ${ }^{1}$, GUIZHI LIU ${ }^{2}$ \\ ${ }^{1}$ Department of Cardiac Function, People's Hospital of Zhengzhou, Zhengzhou City, Henan Province, China \\ ${ }^{2}$ Department of Vasculocardiology, the First Affiliated Hospital of Zhengzhou University, Zhengzhou City, Henan Province, China
}

\begin{abstract}
Objective: To investigate the curative effect of fenofibrate on rats with experimental autoimmune myocarditis (EAM) and its immunological mechanism.

Material and methods: Twenty-four rats were equally randomised into three groups: an EAM group, fenofibrate group, and control group, then a subcutaneous injection of purified pig cardiac myosin was given to the EAM group rats and the fenofibrate group, while equivalent normal saline (NS) was given to the control group. After that, the fenofibrate group received fenofibrate by gavage (100 $\mathrm{mg} /$ $\mathrm{kg} / \mathrm{d})$ and equivalent NS was given to the other groups, lasting for 17 days. Then the rats were sacrificed in order to take heart tissues; HE staining and qRT-PCR method was used to assess the severity of heart failure and mRNA level of cytokines; $N K-\kappa B$ protein content was analyzed by Western-blot. Healthy rat spleen tissue was prepared for splenocyte suspension. Subsequently, splenocytes were administrated similarly to the test in vivo for detecting cytokine mRNA levels.

Results: Compared with the control group, heart weight in EAM group was heavier than in the other groups $(p<0.05)$, and there was severe inflammatory cell infiltration in heart tissue of the EAM group. Th17 cell-related cytokines $m R N A$ levels in the EAM group/induction group were evidently higher than in other groups ( $p<0.05)$; FOX-p3 mRNA level in the EAM group/induction group was lower than other groups, $m R N A$ levels of IL-10 and FOX-p3 in the fenofibrate group were higher than in the EAM group/induction group $(p<0.05)$. Fenofibrate could significantly inhibit the up-regulation of $N F-\kappa B$ protein in EAM rats $(p<0.05)$.

Conclusions: By inhibiting the development of Th17 cells and promoting the differentiation of Tregs, fenofibrate alleviated Treg/Th17 disorder and inhibited inflammation in rats with EAM, thus improving the prognosis.
\end{abstract}

Key words: experimental autoimmune myocarditis, rat, myocardial tissues, Th17 cell, Treg cell.

(Cent Eur J Immunol 2016; 41 (1): 64-70)

\section{Introduction}

Myocarditis is inflammation of the myocardium, often caused by infection of Coxsackie virus, characterise by inflammatory infiltration associated with degeneration and necrosis of myocardial cells. In the course of myocarditis, inflammatory cytokines activate the immune system of patients or experimental animals through direct cytotoxicity and via activation of lymphocyte function. Studies have shown that $\mathrm{T}$ cells, especially $\mathrm{T}$ helper cells, play an important role in the development of myocarditis and inflammation [1]. T helper type 17 (Th17) cells are a subset of $\mathrm{CD}^{+} \mathrm{T}$ helper cells, producing cytokines including interleukin 17 (IL-17) [2], IL-6, IL-21, IL-22, IL-26, tumour necrosis factor, and granulocyte-macrophage colony-stimulating factor (GM-CSF). It has been proven that Th17 cells play important role in development of autoimmune diseases like rheumatoid arthritis, systemic lupus erythematosus, and multiple sclerosis [3, 4]. Recently it has been reported that "classical" Th17 cells, which mainly produce IL-17, are not pathogenic, while GM-CSF is critical for the pathogenicity of Th17 cells [5, 6]. Granulocyte-macrophage colony-stimulating factor induces the differentiation of macrophages and increases the production of proinflammatory cytokines such as IL-6, IL-12, IL-23, or IL-1 $\beta$ from antigen presenting cells, thus resulting in further differentiation of Th17 and Th17 cells [7].

Peroxisome proliferator-activated receptors (PPARs) are a kind of nuclear transcription factor that are activated by ligand, belonging to the type II nuclear receptors superfamily. PPARs include three subtypes: PPAR- $\alpha$, PPAR- $\beta / \delta$, and PPAR- $\gamma$, of which PPAR- $\alpha$ is a master controller of

Correspondence: Guizhi Liu, Department of Vasculocardiology, the First Affiliated Hospital of Zhengzhou University, Jianshe Dong Road, No. 1, 450052, Zhengzhou City, Henan Province, China, e-mail: liugz_vas@126.com Submitted: 16.04.2015; Accepted: 29.12.2015 
cardiac lipid metabolism. Many studies have confirmed that PPAR- $\alpha$ plays a crucial role in cardiac hypertrophy and myocarditis [8]. Peroxisome proliferator-activated receptor $\alpha$ can also inhibit the release of many pro-inflammatory factors, reduce the production of chemotactic factors, and promote the differentiation of $\mathrm{T}$ cells to protective T-cell subsets. Fenofibrate is a PPAR- $\alpha$ agonist widely used in clinics for its effectiveness in reducing cholesterol and triglyceride. Recent studies have demonstrated numerous pleiotropic effects of fenofibrate on the heart, such as preventing the development of myocardial inflammation in angiotensin-II-infused rats, attenuating isoproterenol-induced acute myocardial ischaemic injury, and inhibiting the infiltration of macrophages and $\mathrm{T}$ lymphocytes into the left ventricle $[9,10]$.

Experimental autoimmune myocarditis (EAM) rat model can become into dilated cardiomyopathy (DCM), and the progression of DCM is similar to that of human myocarditis, which makes the EAM rat model a perfect choice for studying the immune mechanism of myocarditis. Moreover, it was found that the activation and differentiation of $\mathrm{T}$ cells, particularly $\mathrm{T}$ regulatory cells (Tregs) and Th17 cells, play an important role in the pathogenesis of EAM. In this study, through the establishment of the EAM model in rats and treatment with fenofibrate, we explored the curative effect of fenofibrate on EAM and the role of Tregs and Th17 cells in it.

\section{Material and methods}

\section{Establishment of the EAM model and specimen collection}

Twenty-four healthy adult male SD rats were selected, weighing 200-220 g. Purified pig cardiac myosin (final concentration $10 \mathrm{mg} / \mathrm{ml}$ ) was diluted with PBS and then fully emulsified in Freund's Complete Adjuvant (FCA) of the same volume. Rats were equally randomly divided into the control group, model group (EAM group), and fenofibrate group $(100 \mathrm{mg} / \mathrm{kg})$. After being anaesthetised, the
EAM group and the fenofibrate group received plantar subcutaneous injection of the above-mentioned antigen $(0.2 \mathrm{ml}$ per rat), while the control group received equivalent normal saline. Then, fenofibrate was given to the fenofibrate group by gavage $(100 \mathrm{mg} / \mathrm{kg} / \mathrm{d})$ and equivalent normal saline was given to the other groups, which lasted for 17 days.

On day 18, the rats were weighed and sacrificed in order to take out heart tissues, then the heart tissues were divided into two parts, and one part was fixed in $10 \%$ neutral formalin for histopathological analysis and the other was put in cryogenic tubes with liquid nitrogen for molecular biological study.

\section{Detection of myocardial histopathology and mRNA level of cytokines in heart tissues and splenocytes}

After being fixed by formalin for 24 hours, myocardial tissues were subjected to ethanol dehydration, paraffin embedding, sectioning, and HE staining.

Frozen myocardial tissues $(100 \mathrm{mg})$ were made into small pieces for extracting the total RNA by Trizol method. Subsequently, reverse transcription reaction was performed to synthesise cDNA. With GAPDH as the reference gene, target genes including IL-17A, IL-6, ROR- $\gamma$ t, IL-23P19, FOX-p3, IL-10, atrial natriuretic peptide (ANP), and brain natriuretic peptide (BNP) were amplified. Primers are shown in Table 1 . The reaction processes were as follows: $95^{\circ} \mathrm{C}, 3 \mathrm{~min} \rightarrow\left(95^{\circ} \mathrm{C}, 15 \mathrm{~s} \rightarrow 60^{\circ} \mathrm{C}, 32 \mathrm{~s}\right)$ $\times 40$ cycles; $95^{\circ} \mathrm{C}, 15 \mathrm{~s} \rightarrow 60^{\circ} \mathrm{C}, 1 \mathrm{~min} \rightarrow 95^{\circ} \mathrm{C}, 15 \mathrm{~s}$, $60^{\circ} \mathrm{C}, 15 \mathrm{~s}$. The $2^{-\Delta \Delta \mathrm{CT}}$ method was used to measure the expression of target genes. $\Delta \Delta \mathrm{C}_{\mathrm{T}}=\left(\mathrm{C}_{\mathrm{T} \text { target }}-\mathrm{C}_{\mathrm{T} \text { reference }}\right)_{\text {treated group }}$ $-\left(\mathrm{C}_{\mathrm{T} \text { target }}-\mathrm{C}_{\mathrm{T} \text { reference }}\right)_{\text {untreated group }}$. In the study, the control group was set as the untreated group.

Spleen tissue of healthy adult rat was taken out under aseptic conditions to prepare the splenocyte suspension. Then, splenocytes were inoculated in six-well plates at $5 \times 10^{4}$ cells $/ \mathrm{ml}$ and divided into control group, induction group, and fenofibrate group. For control group cells, only cell culture medium was given; for induction group and

Table 1. Primers for real-time RT-PCR

\begin{tabular}{|c|c|c|}
\hline Genes & Sense primer & Antisense primer \\
\hline$I L-17 A$ & 5'-tatcagtcccettccttg-3', & 5'-tcctgaacttctaacagctccacca-3' \\
\hline$I L-6$ & 5' -ccgagtagacctcatagtgacctt-3, & 5'-cctattgaaatctgctgctctggtct-3, \\
\hline$I L-23 P 19$ & 5'-gcacactagcctggagtgca-3' & $5^{\prime}$-tgtccgagtccagtaggtgct- $3^{\prime}$ \\
\hline$B N P$ & 5'-gacgggctgaggttgtttta-3' & 5' -actgtggcaagtttgtgctg-3' \\
\hline$A N P$ & 5'-catatggtttttctacagcatga-3, & 5'-tggttgaccgtacagagaagttt-3' \\
\hline$R O R-\gamma t$ & 5'-gcttctctcaggcttttggtc-3' & 5'-tggcttctttgactctgcttc- $3^{\prime}$ \\
\hline$F O X-p 3$ & 5'-tcagacattcgggaagcagtg-3', & 5'-attccgtctccttggttcagc-3' \\
\hline$I L-10$ & 5'-gctatgttgcetgctcttactg-3' & 5'-tctggctgactgggaagtg-3, \\
\hline$G A P D H$ & 5'-atcaccatcttccaggagcga-3' & $5^{\prime}$-agccttctccatggtggtgga- ${ }^{\prime}$ \\
\hline
\end{tabular}


fenofibrate group cells, $4 \mu \mathrm{g} / \mathrm{ml} \mathrm{IL}-6+2 \mu \mathrm{g} / \mathrm{ml}$ transforming growth factor $\beta$ (TGF- $\beta$ ) was added into the culture medium; moreover, fenofibrate $(100 \mu \mathrm{g} / \mathrm{ml})$ was also given to the fenofibrate group cells. After the dosing, all cells were continued culturing for 48 hours in incubators at $37^{\circ} \mathrm{C}$. Then cells were collected in order to draw total RNA by Trizol method and to detect mRNA level of cytokines in splenocytes. This test was conducted three times.

\section{Determination of the content of $\mathrm{NF}-\kappa \mathrm{B}$ and PPAR- $\alpha$ in heart tissues}

Cell nuclear proteins and cytoplasmic proteins in heart tissues were extracted with extraction kits after homogenisation. Then $12 \%$ or $10 \%$ polyacrylamide gel was used to separate $\mathrm{NF}-\kappa \mathrm{B} \mathrm{p} 50$ or $\mathrm{p} 65$ protein, and then the proteins were transferred to nitrocellulose membrane and incubated overnight with primary antibodies (rabbit anti-NF- $\kappa \mathrm{B}$ p50 polyclonal antibody or rabbit anti-NF- $\mathrm{B}$ p65 polyclonal antibody), the second antibody in sequence. With $\beta$-actin as the control, UVIDoc system was used to analyse grey scale values of proteins and calculate the grey ratio of

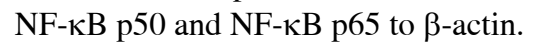

A

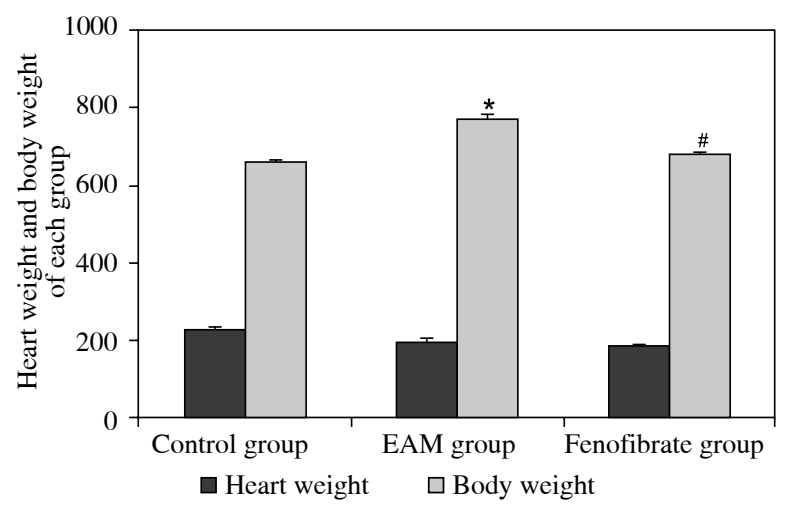

C

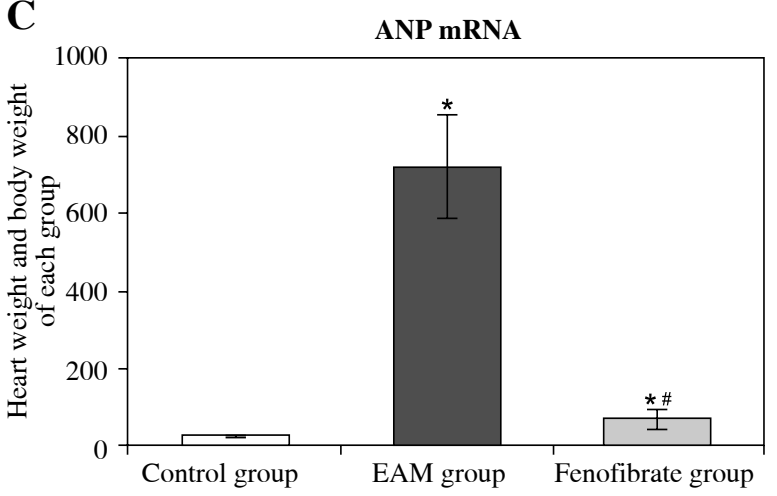

Myocardial tissues were ground in liquid nitrogen, incubated on ice with $200 \mu \mathrm{l}$ precooled protein extraction reagent for 20 minutes, and centrifuged at $10,000 \mathrm{~g}$ for 15 minutes. Then the supernatant was collected and Western-blot was performed. The grey ratio of PPAR- $\alpha$ to $\beta$-actin was calculated.

\section{Data statistics}

All the experimental data were represented as mean \pm SD and analysed by SPSS18.0 software. One-Way ANOVA was conducted for comparison between groups; when there was significant difference in variances, the q test was adopted. When $p<0.05$ the differences were statically significant.

\section{Results}

\section{Influence of fenofibrate on rat myocardial lesions}

Compared with the control group, the heart weight of the EAM group was heavier than in the control group and the fenofibrate group $(p<0.05)$; the ratio of heart weight/ body weight (HW/BW) of the EAM group and the feno-

\section{B}

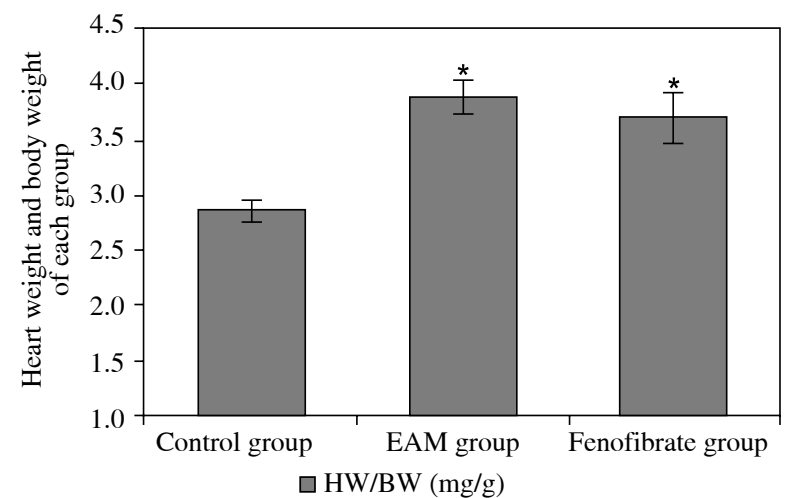

D

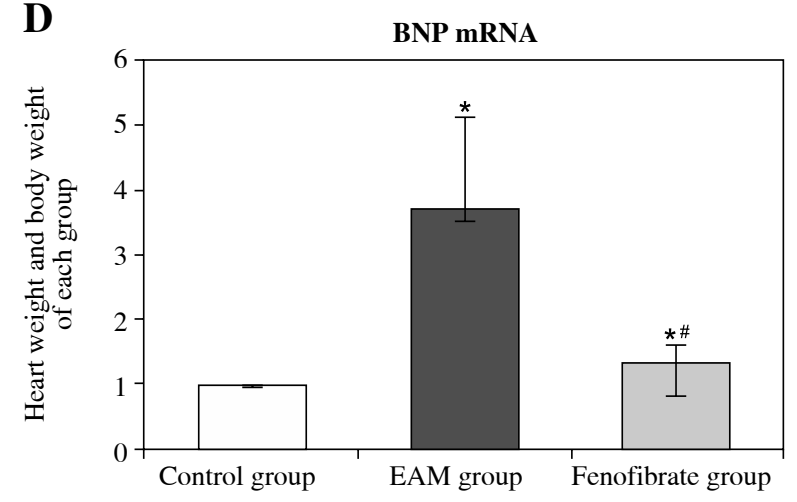

"vs. control group, $p<0.05$; ${ }^{*} v s$. EAM group, $p<0.05$. The same for subsequent figures

Fig. 1. Body weight, heart weight, the ratio of heart weight/body weight (HW/BW), and mRNA expression level of ANP and BNP in heart tissues of rats (eight rats per group). A) Body weight and heart weight; B) the ratio of heart weight/ body weight, HW/BW; C) ANP mRNA expression; D) BNP mRNA expression 
fibrate group were both higher than in the control group $(p<0.05)$ (Fig. 1A, B). The mRNA contents of ANP and $\mathrm{BNP}$ in the EAM group and the fenofibrate group were higher than those in the control group, and those in the fenofibrate group were lower than in the EAM group $(p<0.05)$ (Fig. 1C, 1D). Figure 2 showed that there was no inflammatory cell infiltration in the control group, while there was severe inflammatory cell infiltration in the EAM group and slight inflammatory cell infiltration in the fenofibrate group.

\section{Influence of fenofibrate on cytokines mRNA level in heart tissues and splenocytes of rats}

Figure 3 and Figure 4 show that mRNA levels of IL-6, IL-17A, ROR- $\gamma$ t, and IL-23P19 of the EAM group/induction group in heart tissues/splenocytes were evidently higher than in other groups $(p<0.05)$. Conversely, the FOX-p3 mRNA level in the EAM group/induction group was lower than in other groups, and in the fenofibrate group it was higher than in the control group $(p<0.05)$; IL-10 mRNA level in the EAM group/induction group was higher than in the control group, and in the fenofibrate group it was higher than in the EAM group/induction group $(p<0.05)$.

\section{Levels of NF- $\kappa \mathrm{B}$ p65/p50 and PPAR- $\alpha$ protein in heart tissues}

In order to validate whether fenofibrate can modify the expression of inflammatory factors in EAM rats through $\mathrm{NF}-\kappa \mathrm{B}$, and considering NF- $\kappa \mathrm{B}$ usually exists in the cytoplasm in the form of p65/p50 dimer, we analysed the level of NF- $\kappa \mathrm{B}$ p50 and p65 protein in the rat heart. Table 2 and Fig. 5 showed that fenofibrate could significantly inhibit the up-regulation of NF- $\kappa \mathrm{B}$ p50 and p65 proteins of EAM rats $(p<0.05)$. Considering that fenofibrate is a PPAR- $\alpha$ agonist, we also measured the expression of PPAR- $\alpha$ protein, and it showed that the PPAR- $\alpha$ level in the fenofibrate group was higher than that in other groups $(p<0.05)$.

\section{Discussion}

The activation and differentiation of T cells greatly influence the pathogenesis of EAM [11]. When there is no inflammation, TGF- $\beta 1$ produced by the immune system would inhibit the proliferation of $\mathrm{T}$ cells and induce the differentiation of Tregs, thus maintaining the immune tolerance, but when infection exists, considerable IL-6 is produced and the differentiation of Tregs is inhibited, so the differentiation of Th17 cells will be induced by IL-6 in
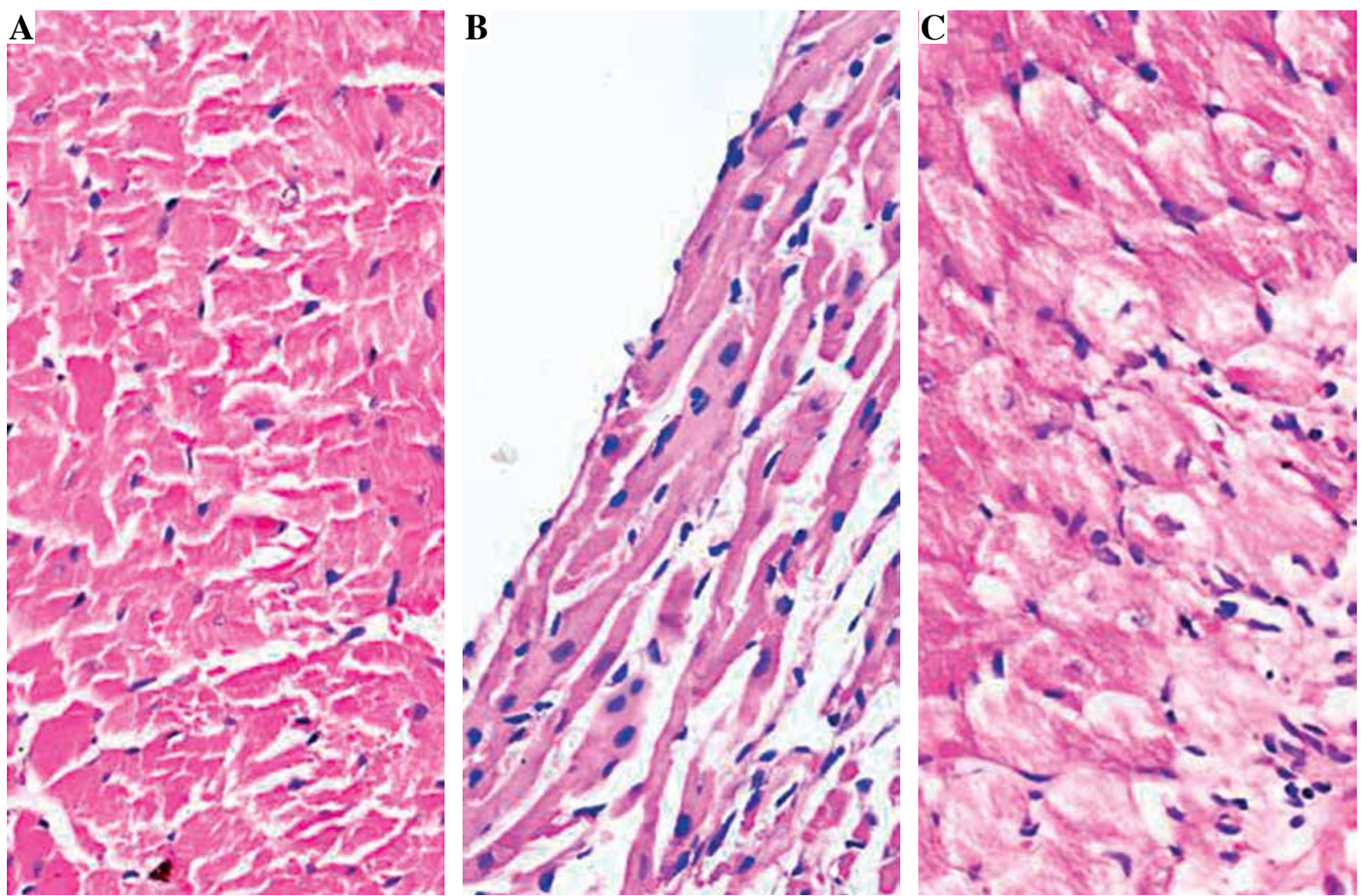

Fig. 2. Histopathological analysis of rat myocardial tissues by HE staining (original magnification $400 \times$ ). A) Control group; B) EAM group; C) Fenofibrate group 
A

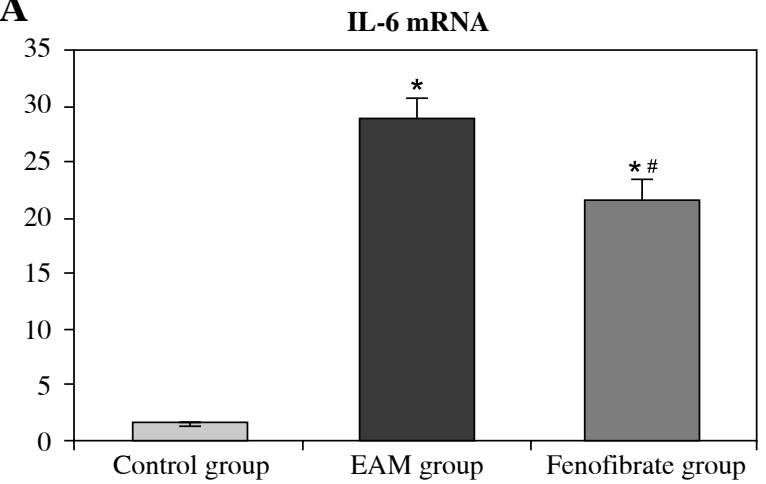

C

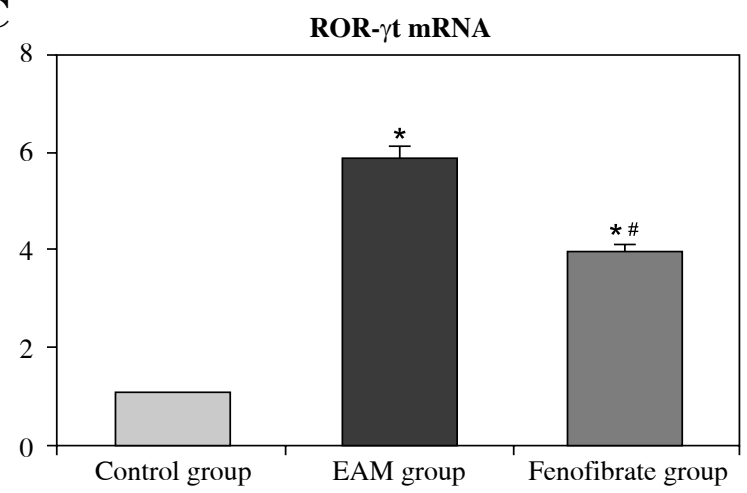

$\mathbf{E}$

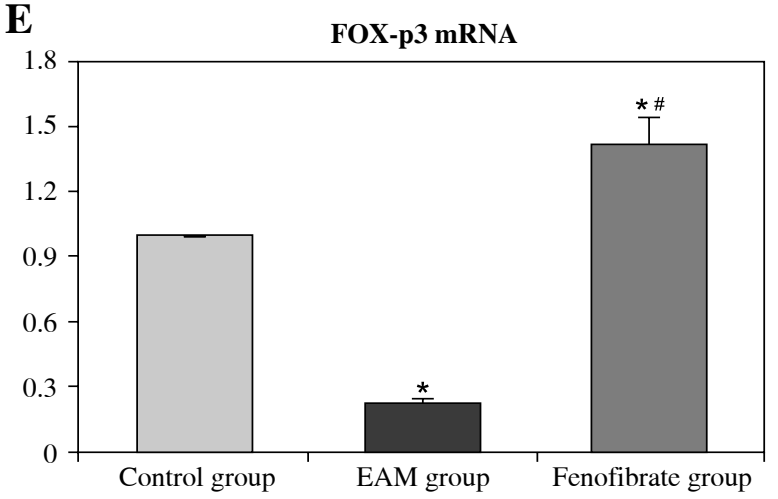

B

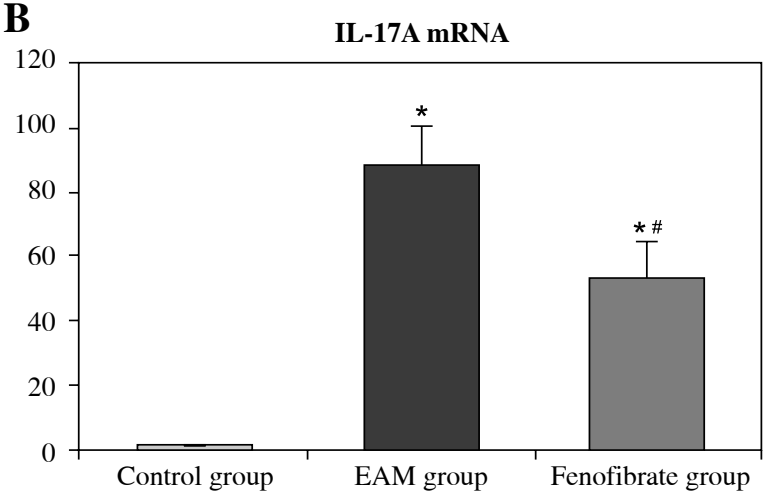

D

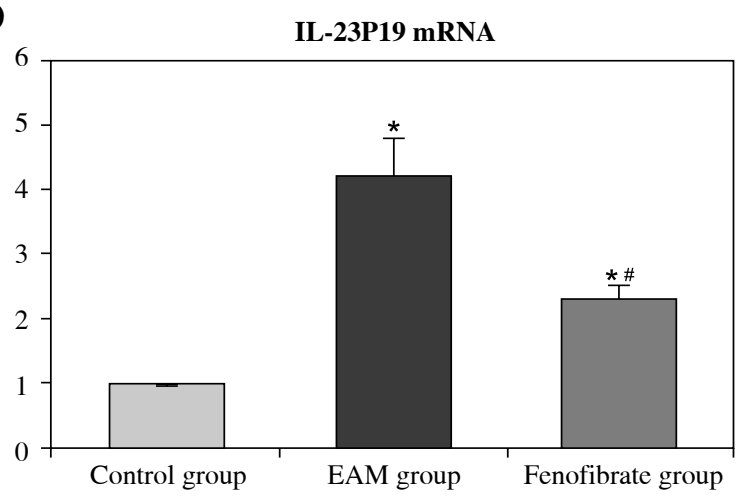

F

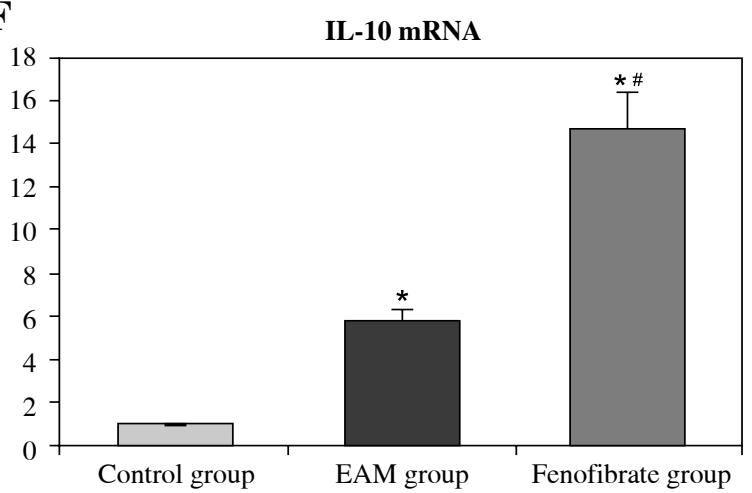

Fig. 3. mRNA expression levels of cytokines in heart tissues of each group (fold change relative to control group)

combination with TGF- $\beta$, thus mediating pro-inflammatory reactions $[12,13]$.

This study showed that fenofibrate was effective for treating EAM by alleviating the inflammatory cell infiltration and inhibiting the increase in heart weight caused by inflammation. Meanwhile, fenofibrate reduced the content of heart failure markers (ANP and BNP), and as a PPAR- $\alpha$ agonist it increased PPAR- $\alpha$ protein expression. Moreover, fenofibrate could reduce the expression of Th17-related cytokines (IL-6, IL-17A, ROR- $\gamma$ t, and IL-23P19) and increase Treg-related cytokines (FOX-p3 and IL-10). These results imply that fenofibrate had a notable protective effect on the hearts of rats with myocarditis [14].
It was proven that IL-6 can induce autocrine secretion of IL-21 in Th17 cells, and IL-21 can not only induce IL-23 expression by positive feedback loop but also induce ROR- $\gamma \mathrm{t}$ expression through its cooperation with IL-23, thus promoting IL-17 expression [15, 16]. As a core transcription factor in the development of Tregs, FOX-p3 mainly regulates the transformation of nadve $\mathrm{T}$ cells to Tregs. When FOX-p3 expression is increased in T cells, it can inhibit the activity of ROR- $\gamma$ t, thus inhibiting the differentiation of T cells to Th17 cells $[17,18]$. Based on the results of the study, we supposed that the effectiveness of fenofibrate on myocarditis is realised by inhibiting the differentiation and development of Th17 cells [19]. 
A

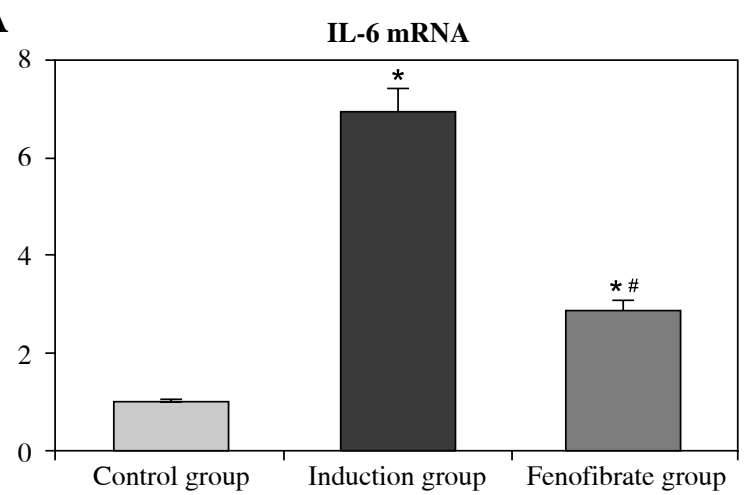

C

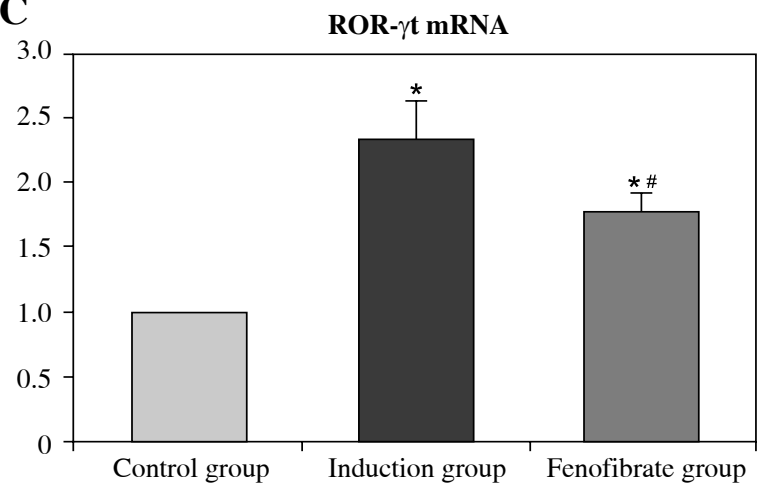

$\mathbf{E}$

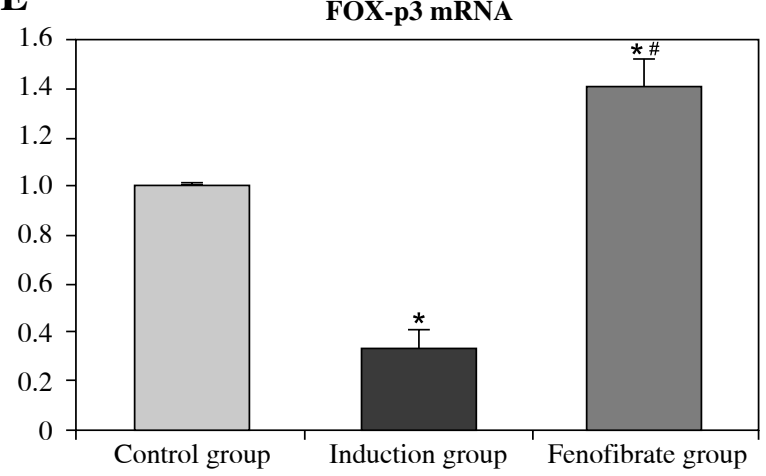

B

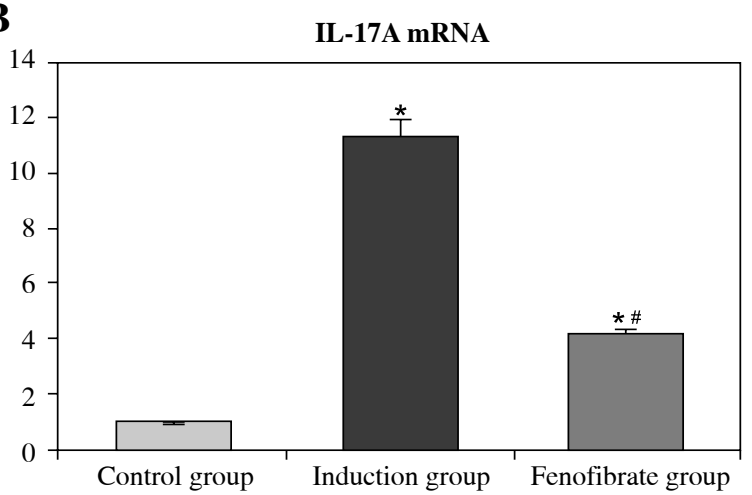

D

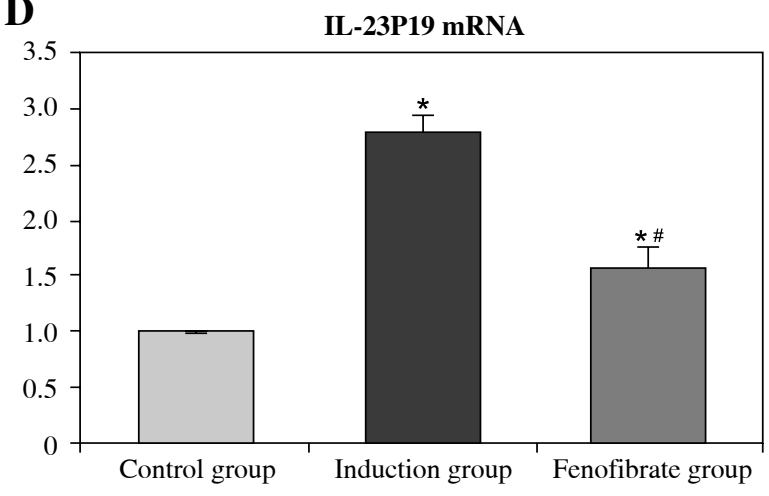

F

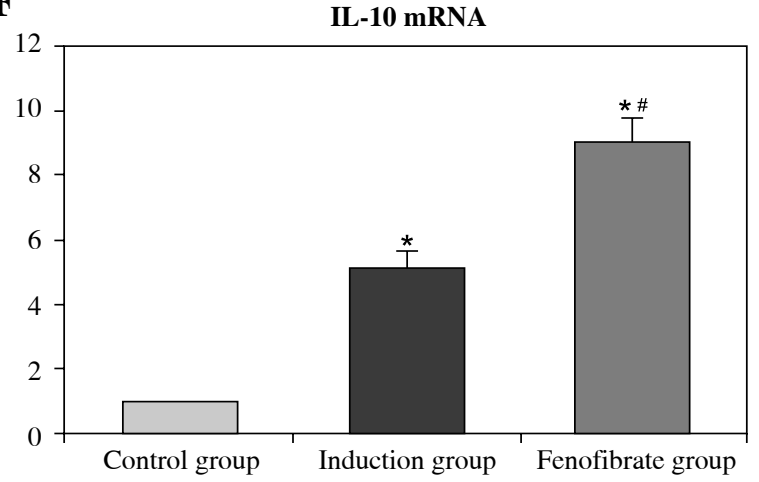

Fig. 4. mRNA expression levels of cytokines in rat splenocytes in vitro (fold change relative to control group)

Table 2. Semiquantitative analysis of NF- $\kappa \mathrm{B}$ p50, p65, and PPAR- $\alpha$ protein expression in heart tissues

\begin{tabular}{|c|c|c|c|}
\hline Groups & NF- $\kappa$ B p50 & NF- $\kappa B$ p65 & PPAR- $\alpha$ \\
\hline Control group & $0.327 \pm 0.013$ & $0.406 \pm 0.010$ & $0.473 \pm 0.016$ \\
\hline EAM group & $1.035 \pm 0.041^{*}$ & $1.354 \pm 0.037 *$ & $0.565 \pm 0.023$ \\
\hline Fenofibrate group & $0.596 \pm 0.023^{\text {*\# }}$ & $0.738 \pm 0.022 * \#$ & $1.268 \pm 0.049 * \#$ \\
\hline
\end{tabular}

*vs. control group, $p<0.05$; \# vs. EAM group, $p<0.05$

In addition, we also observed that PPAR- $\alpha$ protein expression increased significantly in the fenofibrate group. PPAR $-\alpha$ can inhibit NF- $\kappa$ B expression by inhibiting the activity of the NF- $\kappa$ B p65 subunit, thus modifying inflammatory factor expression and inhibiting local inflammation
$[20,21]$. Therefore, when fenofibrate elevated PPAR- $\alpha$ expression, the expression of NF- $\kappa \mathrm{B}$ was restrained in EAM rats, which caused down-regulation of IL-6, IL-17, and IL-23P19, and inhibited the differentiation of Th17 cells. Because of the significant role of FOX-p3 and IL-10 


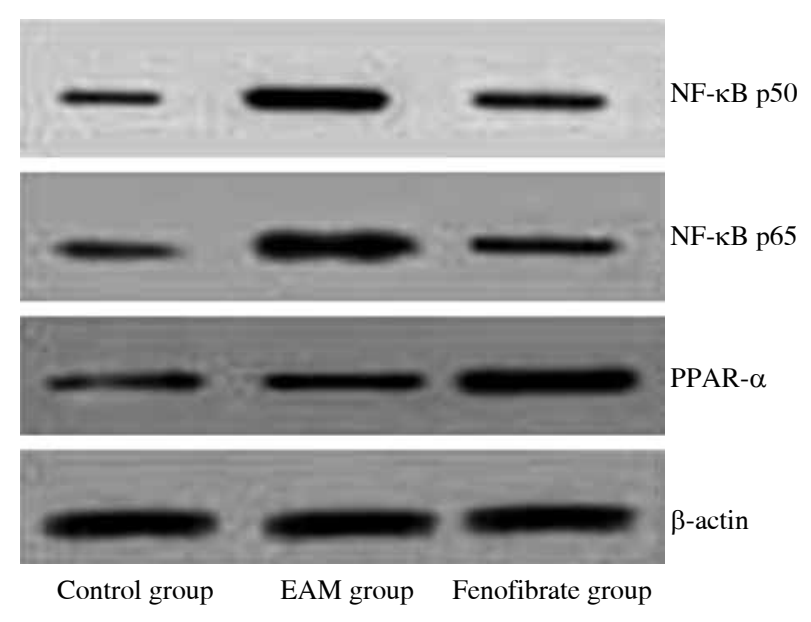

Fig. 5. Immunoblot analysis of $N F-\kappa B$ p50/p65 and PPAR- $\alpha$ protein

during Treg differentiation and development, the up-regulation of FOX-p3 and IL-10 causes an increase in the content and activity of Tregs. The results of our study indicated that there was a certain reciprocal relationship between Tregs and Th17 cells [22, 23]. When fenofibrate was given, it may have corrected the imbalance between Tregs and Th17 cells. In such a case, the therapeutic outcome and prognosis would be improved.

\section{Conclusions}

In EAM rats, via inhibition of the development and differentiation of Th17 cells and promotion of the differentiation of Tregs, fenofibrate can modify Treg/Th17 disorder, inhibit inflammation, and improve the prognosis.

\section{The authors declare no conflict of interest.}

\section{References}

1. Cihakova D, Rose NR (2008): Pathogenesis of myocarditis and dilated cardiomyopathy. Adv Immunol 99: 95-114.

2. Park H, Li Z, Yang XO, et al. (2005): A distinct lieage of $\mathrm{CD} 4+\mathrm{T}$ cells regulates tissue inflammation by producing interleukin 17. Nat Immunol 6: 1133-1141.

3. Joosten LA, Abdollahi-Roodsaz S, Heuvelmans-Jacobs M, et al. (2008): T cell dependence of chronic destructive murine arthritis induced by repeated local activation of Toll-like receptor-driven pathways: crucial role of both interleukin- 1 beta and interleukin-17. Arthritis Rheum 58: 98-108.

4. Yang J, Chu Y, Yang X, et al. (2009): Th17 and natural Treg cell population dynamics in systemic lupus erythematosus. Arthritis Rheum 60: 1472-1483.

5. El-Behi M, Ciric B, Dai H, et al. (2011): The encephalitogenicity of $\mathrm{T}(\mathrm{H}) 17$ cells is dependent on IL-1- and IL-23induced production of the cytokine GM-CSF. Nat Immunol 12: $568-575$.
6. Codarri L, Gyülvészi G, Tosevski V, et al. (2011): ROR $\gamma \mathrm{t}$ drives production of the cytokine GM-CSF in helper T cells, which is essential for the effector phase of autoimmune neuroinflammation. Nat Immunol 12: 560-567.

7. Shiomi A, Usui T (2015): Privotal roles of GM-CSF in autoimmunity and inflammation. Mediators Inflamm 2015: 568543.

8. Planavila A, Iglesias R, Giralt M, Villarroya F (2011): Sirt1 acts in association with PPAR $\alpha$ to protect the heart from hypertrophy, metabolic dysregulation, and inflammation. Cardiovasc Res 90: 276-284.

9. Diep QN, Benkirane K, Amiri F, Cohn JS, Endemann D, Schiffrin EL (2004): PPARalpha activator fenofibrate inhibits myocardial inflammation and fibrosis in antiotensin II-infused rats. J Mol Cell Cardiol 36: 295-304.

10. Yuan J, Wu J, Han ZG (2008): Fenofibrate improves energy metabolism and attenuates isoproterenol induced acute myocardial ischemic injury in rats via PPAR alpha activation. Zhonghua Xin Xue Guan Bing Za Zhi 36: 847-850.

11. Kamata S, Miyagawa S, Fukushima S, et al. (2014): Targeted delivery of adipocytokines into the heart by induced adipocyte cell-sheet transplantation yields immune tolerance and functional recovery in autoimmune-associated myocarditis in rats. Circ J 79: 169-179.

12. Hasan M, Neumann B, Haupeltshofer S, et al. (2015): Activation of TGF- $\beta$-induced non-Smad signaling pathways during Th17 differentiation. Immunol Cell Biol 93: 662-672.

13. Bettelli E, Carrier Y, Gao W, et al. (2006): Reciprocal developmental pathways for the generation of pathogenic effector TH17 and regulatory T cells. Nature 441: 235-238.

14. Balakumar P, Rohilla A, Mahadevan N (2011): Pleiotropic actions of fenofibrate on the heart. Pharmacol Res 63: 8-12.

15. Ivaov II, Zhou L, Littman DR (2007): Transcriptional regulation of Th17 cell differentiation. Semin Immunol 9: 409-417.

16. Zhou L, Ivanov II, Spolski R, et al. (2007): IL-26 programs $\mathrm{T}(\mathrm{H}) 217$ cell differentiation by promoting sequential engagement of the IL221 and IL223 pathways. Nat Immunol 8: $967-974$.

17. Chen W, Jin W, Hardegen N, et al. (2003): Conversion of peripheral CD4+CD25- nadve T cells to $\mathrm{CD} 4+\mathrm{CD} 25+$ regulatory $\mathrm{T}$ cells by TGF-beta induction of transcription factor Foxp3. J Exp Med 198: 1875-1886.

18. Zhang F, Meng G, Strober W (2008): Ineractions among the transcription factors Runx1, RORgammat and Foxp3 regulate the differentiation of interleukin 17-producing T cells. Nat Immunol 9: 1297-1306.

19. Zhou Z, Sun W, Liang Y, et al. (2012): Fenofibrate inhibrated the differentiation of $\mathrm{T}$ helper 17 cells in vitro. PPAR Res 2012: 145654.

20. Jeon Y, Jung Y, Kim MC, et al. (2014): Sargahydroquinoic acid inhibits TNF $\alpha$-induced AP-1 and NF- $\mathrm{BB}$ signaling in Ha$\mathrm{CaT}$ cells through PPAR $\alpha$ activation. Biochem Biophys Res Commun 450: 1553-1559.

21. Wang W, Lin Q, Lin R, et al. (2013): PPAR $\alpha$ agonist fenofibrate attenuates TNF- $\alpha$-induced CD40 expression in 3T3-L1 adipocytes via the SIRT1-dependent signaling pathway. Exp Cell Res 319: 1523-1533.

22. Acuff NV, Li X, Kirkland R, Nagy T, Watford WT (2015): Tumor Progression Locus 2 Differentially Regulates IFN $\gamma$ and IL-17 Production by Effector CD4+ T Cells in a T Cell Transfer Model of Colitis. PLoS One 10: e0119885.

23. Abe M, Hiasa Y, Onji M (2013): T helper 17 cells in autoimmune liver diseases. Clin Dev Immunol 2013; 2013: 607073. 